\title{
A possible role of osteocalcin in the regulation of insulin secretion: human in vivo evidence?
}

\author{
Eva Kassi and Athanasios G Papavassiliou \\ Department of Biological Chemistry, University of Athens Medical School, 75, Mikras Asias Street, 11527 Athens, Greece \\ (Correspondence should be addressed to A G Papavassiliou; Email: papavas@med.uoa.gr)
}

\begin{abstract}
Recent studies have indicated a novel function for skeleton unraveling its importance in the control of energy metabolism. In the present commentary, we speculate on the meaning for bone to act as a 'rheostat' modulating glucose metabolism, and how the primitive way of communication
\end{abstract}

between bone and energy metabolism through switch on/off genes (like Ptprv) evolved to a more complicated 'talking' via gain/loss of hormones activity (like osteocalcin) by carboxylation/decarboxylation process.

Journal of Endocrinology (2008) 199, 151-153

\section{Introduction}

For decades the skeleton has been thought of as a calcified, less active tissue providing a strong framework to support the body and implicated in calcium homeostasis. Recent studies have now suggested a novel function of the skeleton in the regulation of energy metabolism. Indeed, in mice, osteocalcin (OC), a molecule produced by osteoblasts has been found to increase both the secretion and sensitivity of insulin, in addition to increasing the number of insulin-producing cells and reducing stores of fat. Although new aspects of metabolism regulation by the skeleton are uncovered, crucial questions need to be answered: what is the meaning of this crosstalk between bone and energy metabolism, and has this communication been modified through evolution?

\section{Role of carboxylation process}

Vitamin $\mathrm{K}$ is a fat-soluble vitamin found in a variety of food sources. It refers to a family of compounds, the most common consumed form being phylloquinone (vitamin $\mathrm{K}_{1}$ ) that is found in plants. Non-plant forms of vitamin $\mathrm{K}$, the menaquinones, are present in some animal foods and in products derived from bacterial fermentation. It is known that vitamin $\mathrm{K}$ is not only necessary for coagulation, but also acts as a cofactor helping to introduce carbon dioxide (carboxylation) into glutamic acid (Glu) residues of $\sim 12$ proteins. The resulting amino acid, $\gamma$-carboxyglutamic acid (Gla), in the presence of vitamin $\mathrm{K}$ has calcium-binding properties that confer function to all vitamin $\mathrm{K}$-dependent proteins, also known as Gla-containing proteins.
Among these proteins are $\mathrm{OC}$ and matrix Gla protein (MGP). It is known that OC, the most abundant noncollagenous protein produced by osteoblasts, through the posttranslational carboxylation process gains high affinity for mineral ions thus binding to hydroxyapatite (Hauschka et al. 1989). Although loss- and gain-of-function experiments in animals have failed to identify a function for OC in extracellular matrix mineralization in vivo (Ducy et al. 1996, Murshed et al. 2004), recent data have shown that vitamin $\mathrm{K}_{1}$ insufficiency followed by higher levels of undercarboxylated OC leads to increased susceptibility to vertebral fracture independent from bone mineral density (Tsugawa et al. 2008). Moreover, circulating levels of undercarboxylated $\mathrm{OC}$ comprise an indicator of risk for hip fracture (Seibel et al. 1997).

A large volume of studies have indicated that vitamin $\mathrm{K}$-dependent proteins bear additional activities that extend their roles beyond hemostatic and bone metabolism, perhaps in vascular calcification and atherosclerotic complications. Gene deletion studies in mice have shown that MGP is an inhibitor of calcification (Luo et al. 1997). Moreover, Price et al. (1998) showed that inhibition of vitamin K epoxide reductase complex, subunit 1 by warfarin resulting in undercarboxylation of MGP leads to medial calcification of the arterial vessel wall. Thus, it could be said that carboxylation process is offered as a linkage between osteoporosis and atherosclerosis.

Sakamoto et al. (1999) in an attempt to elucidate the role of vitamin $\mathrm{K}$ in the pancreas, administered vitamin $\mathrm{K}$ to young male volunteers and noticed that the group with low vitamin $\mathrm{K}$ intake displayed lower levels of insulin and lower insulinogenic index (incremental immunoreactive insulin over incremental plasma glucose, $0-30 \mathrm{~min}$ after $75 \mathrm{~g}$ oral 
glucose loading, indicating the early phase insulin secretion). Subsequently, the same research team (Sakamoto et al. 2000) administered menaquinone-4 (90 mg/day for 1 week) in young male volunteers and examined the insulin and glucose levels during $75 \mathrm{~g}$ oral glucose loading before and after the administration of vitamin K. Interestingly, the subjects who had higher serum descarboxyprothrombin levels - i.e., lower vitamin $\mathrm{K}$ - exhibited the largest decrease in insulin secretion, suggesting that vitamin $\mathrm{K}$ may play an important role in the acute insulin response in glucose tolerance.

In view of a recent report (Lee et al. 2007), according to which uncarboxylated $\mathrm{OC}$ induces in vitro the expression of insulin, the question arises whether the carboxylation of $\mathrm{OC}$ - triggered by vitamin $\mathrm{K}$ - was responsible for alterations in insulin response in the young male volunteers. Also, does the process of carboxylation/decarboxylation in the $\beta$-cell gain significance and warrant the presence of glutamic acid decarboxylase (GAD) in pancreatic islets? Although the presence of GAD in pancreatic islets has been known since the 1970s (Okada et al. 1976) and is considered to be one of the strongest candidate autoantigens involved in triggering $\beta$-cell-specific autoimmunity (Yoon et al. 1999), its exact role still remains elusive. However, GAD has been shown to increase in islet cultures in a medium with a high glucose concentration (Kämpe et al. 1989), posing a role of decarboxylation process in insulin secretion.

\section{Bone and energy metabolism cross talk}

It has recently been verified that a hormone regulating energy metabolism, leptin, through binding to its receptor on hypothalamic neurons and using the sympathetic tone and cocaine- and amphetamine-regulated transcript regulates bone function (Karsenty 2006).

Searching for candidate genes that mediate the opposite regulation, of energy metabolism by skeleton, Lee et al. (2007) identified PTPRV that encodes a receptor-like transmembrane protein tyrosine phosphatase present in embryonic stem cells, Sertoli cells, and osteoblasts; the name of the protein it encodes is osteotesticular protein tyrosine phosphatase (PTPRV; Mauro et al. 1994). Notably, although Ptprv expression is induced during osteoblast differentiation in vitro, there is no skeletal abnormality in Ptpr ${ }^{-1-}$ mice (Dacquin et al. 2004).

Lee et al. (2007) by inactivating PTPRV in a classic and in an osteoblast-specific manner, found an increase in $\beta$-cell proliferation, insulin secretion as well as insulin sensitivity - the latter through increasing the expression of adiponectin, an adipokine known to enhance insulin sensitivity (Yamauchi et al. 2001).

Surprisingly, Bglap $1^{-/-}$mice - originally generated by Ducy et al. (1996) and known to develop a phenotype marked by higher bone formation without impairing bone resorption - were glucose intolerant and fat, displaying the opposite phenotype of Ptpr ${ }^{-/-}$mice. According to their findings, the uncarboxylated OC regulated glucose homeostasis in tprv $^{-/-}$mice, whilst only uncarboxylated OC induced the expression of insulin, $\beta$-cell proliferation and expression of adiponectin in adipocytes, in co-culture assays (Lee et al. 2007), albeit in different concentrations (Ferron et al. 2008). These results seem to contradict the aforementioned human in vivo findings of Sakamoto et al. (2000), although it should be mentioned that Vestri et al. (2008, unpublished data) studying the role of $\mathrm{OC}$ in human metabolism found that levels of uncarboxylated OC tended to be lower albeit not significantly - in normoglycemic insulin resistant as well as untreated type 2 diabetes mellitus (T2DM) patients compared with normoglycemic insulin sensitive patients, concluding that $\mathrm{OC}$ is independently related to insulin sensitivity and fasting glucose and these interactions are primarily due to the uncarboxylated form of OC.

In as much as atherosclerosis, osteoporosis, and impairment of $\beta$-cell function constitute three of the major components of the aging process in humans progressing in parallel, one might expect them to be affected by the same factor - in this case a common biochemical process like carboxylation of Gla-containing proteins - in a similar manner. It could be discounted if, for example, vitamin $\mathrm{K}$ that is present in all body tissues, through carboxylation of bone and MGP, positively affects bone formation and protects from vascular calcification while impairing $\beta$-cell insulin secretion.

\section{Evolutional aspect of the communication between bone and glucose metabolism}

Could differences between species account for these discrepancies between animal model and human findings? It may be so, since PTPRV, this important signaling molecule for the in vitro progression from a pre-osteoblast to a mature, mineralizing cell (and which has been inactivated in Lee et al's experiments), is the only PTPase whose function has been lost during the evolution process between rodent and human (Cousin et al. 2004). Looking back at the earlier stages of vertebrate evolution, a need for a strong musculoskeletal system and to a lesser extent for insulin secretion can be recognized. In fact, a strong musculoskeletal could provide to the animal, by fighting, food for energy consumption. Although for some tissues (i.e., brain, erythrocytes) glucose serves as a vital and unique metabolic fuel, these tissues are insulin independent for glucose uptake, whereas in tissues like muscles the need for insulin, at the earlier stages of vertebrate evolution, was probably less, since fighting could serve as a physical activity known to result in a persistent increase in insulin action in skeletal muscle, enhancing, perse, glucose uptake through SLC2A4 translocation (Röckl et al. 2008). Along this line and in view of Lee et al.'s findings a role of a gene link between skeleton and glucose metabolism could be recognized for PTPRV, since switched on it provided good skeletal health - the major need going back evolutionarily - and switched off it could induce $\beta$-cell proliferation, insulin secretion and sensitivity - the major need at the late stages of evolution due to less physical activity and more food consumption. These reciprocal regulations between bone and energy metabolism mediated by PTPRV were in favor 
of bone, whereas it seems to turn in favor of energy metabolism going on evolutionarily.

\section{Considerations}

Missing PTPRV, still remains the necessity of a mediator for communication between skeletal and energy metabolism, since the skeleton is a huge endocrine organ that can easily reflect the mode of living (bone is highly responsive to mechanical forces) and send a message to the energy metabolism not only acutely (insulin secretion) but also probably in a more permanent manner ( $\beta$-cell proliferation). OC, a molecule found to be induced by mechanical stimuli (physical activity) (Rath et al. 2008 ), may participate in the regulation of $\beta$-cell proliferation, insulin secretion and insulin sensitivity in humans not only through its secretion but also via a tissue - and cell-specific carboxylation/decarboxylation process, with the latter offering a more fine and short-term regulation. Furthermore, although multiple signaling pathways have been found to act synergistically to mediate physical exercise-stimulated glucose transport through translocation of SLC2A4 (Röckl et al. 2008), the search for other possible candidates is ongoing; among them the possible role of OC may warrant investigation.

Thus, it could be speculated that the evolutional differences between mice and humans in skeletogenesis may be expanded and influence the cross talk between energy metabolism and the skeleton.

In conclusion, it can be said that there is undoubtedly a reason for the skeleton to act as a 'rheostat' regulating glucose metabolism, but it seems that the rather primitive way of communication between bone and energy metabolism via switch on/off genes (like Ptprv) evolved to a more complicated and/or delicate 'talking' through gain/loss of activity of hormones (like carboxylated/decarboxylated OC) suiting the purpose of evolution.

\section{Declaration of interest}

The authors declare that there is no conflict of interest that would prejudice the impartiality of this scientific work.

\section{Funding}

This research did not receive any specific grant from any funding agency in the public, commercial or not-for-profit sector.

\section{References}

Cousin W, Courseaux A, Ladoux A, Dani C \& Peraldi P 2004 Cloning of hOST-PTP: the only example of a protein-tyrosine-phosphatase the function of which has been lost between rodent and human. Biochemical and Biophysical Research Communications 321 259-265.

Dacquin R, Mee PJ, Kawaguchi J, Olmsted-Davis EA, Gallagher JA, Nichols J, Lee K, Karsenty G \& Smith A 2004 Knock-in of nuclear localised betagalactosidase reveals that the tyrosine phosphatase Ptprv is specifically expressed in cells of the bone collar. Developmental Dynamics 229 826-834.
Ducy P, Desbois C, Boyce B, Pinero G, Story B, Dunstan C, Smith E, Bonadio J, Goldstein S, Gundberg C et al. 1996 Increased bone formation in osteocalcin deficient mice. Nature 382 448-452.

Ferron M, Hinoi E, Karsenty G \& Ducy P 2008 Osteocalcin differentially regulates beta cell and adipocyte gene expression and affects the development of metabolic diseases in wild-type mice. PNAS 105 5266-5270.

Hauschka PV, Lian JB, Cole DE \& Gundberg CM 1989 Osteocalcin and matrix Gla protein: vitamin K-dependent proteins in bone. Physiological Reviews 69 990-1047.

Kämpe O, Andersson A, Björk E, Hallberg A \& Karlsson FA 1989 Highglucose stimulation of $64,000-\mathrm{Mr}$ islet cell autoantigen expression. Diabetes 38 1326-1328.

Karsenty G 2006 Convergence between bone and energy homeostases: leptin regulation of bone mass. Cell Metabolism 4 341-348.

Lee NK, Sowa H, Hinoi E, Ferron M, Ahn JD, Confavreux C, Dacquin R, Mee PJ, McKee MD \& Jung DY 2007 Endocrine regulation of energy metabolism by the skeleton. Cell 130 456-469.

Luo G, Ducy P, McKee MD, Pinero GJ, Loyer E, Behringer RR \& Karsenty G 1997 Spontaneous calcification of arteries and cartilage in mice lacking matrix GLA protein. Nature 386 78-81.

Mauro LJ, Olmsted EA, Skrobacz BM, Mourey RJ, Davis AR \& Dixon JE 1994 Identification of a hormonally regulated protein tyrosine phosphatase associated with bone and testicular differentiation. Journal of Biological Chemistry 269 30659-30667.

Murshed M, Schinke T, McKee MD \& Karsenty G 2004 Extracellular matrix mineralization is regulated locally; different roles of two gla-containing proteins. Journal of Cell Biology 165 625-630.

Okada Y, Taniguchi H \& Schimada C 1976 High concentration of GABA and high glutamate decarboxylase activity in rat pancreatic islets and human insulinoma. Science 194 620-622.

Price PA, Faus SA \& Williamson MK 1998 Warfarin causes rapid calcification of the elastic lamellae in rat arteries and heart valves. Arteriosclerosis, Thrombosis, and Vascular Biology 18 1400-1407.

Rath B, Nam J, Knobloch TJ, Lannutti JJ \& Agarwal S 2008 Compressive forces induce osteogenic gene expression in calvarial osteoblasts. Journal of Biomechanics 41 1095-1103.

Röckl KS, Witczak CA \& Goodyear LJ 2008 Signaling mechanisms in skeletal muscle: acute responses and chronic adaptations to exercise. IUBMB Life 60 145-153.

Sakamoto N, Nishiike T, Iguchi H \& Sakamoto K 1999 Relationship between acute insulin response and vitamin $\mathrm{K}$ intake in healthy young male volunteers. Diabetes, Nutrition and Metabolism 12 37-41.

Sakamoto N, Nishiike T, Iguchi H \& Sakamoto K 2000 Possible effects of one week vitamin $\mathrm{K}$ (menaquinone-4) tablets intake on glucose tolerance in healthy young male volunteers with different descarboxy prothrombin levels. Clinical Nutrition 19 259-263.

Seibel MJ, Robins SP \& Bilezikian JP 1997 Serum undercarboxylated osteocalcin and the risk of hip fracture. Journal of Clinical Endocrinology and Metabolism 82 717-718.

Tsugawa N, Shiraki M, Suhara Y, Kamao M, Ozaki R, Tanaka K \& Okano T 2008 Low plasma phylloquinone concentration is associated with high incidence of vertebral fracture in Japanese women. Journal of Bone and Mineral Metabolism 26 79-85.

Yamauchi T, Kamon J, Waki H, Terauchi Y, Kubota N, Hara K, Mori Y, Ide T, Murakami K, Tsuboyama-Kasaoka N et al. 2001 The fat-derived hormone adiponectin reverses insulin resistance associated with both lipoatrophy and obesity. Nature Medicine 7 941-946.

Yoon JW, Yoon CS, Lim HW, Huang QQ, Kang Y, Pyun KH, Hirasawa K, Sherwin RS \& Jun HS 1999 Control of autoimmune diabetes in NOD mice by GAD expression or suppression in beta cells. Science 284 1183-1187.

Received in final form 14 July 2008

Accepted 21 July 2008

Made available online as an Accepted Preprint

21 July 2008 